\title{
Common amino acid substitutions in insulin receptor substrate-4 are not associated with Type II diabetes mellitus or insulin resistance
}

\author{
K. Almind ${ }^{1}$, S. K. Frederiksen ${ }^{1}$, M. G. Ahlgren ${ }^{1}$, S. Urhammer ${ }^{1}$, T. Hansen ${ }^{1}$, J. O. Clausen ${ }^{2}$, O. Pedersen ${ }^{1}$ \\ ${ }^{1}$ Steno Diabetes Center and Hagedorn Research Institute, Copenhagen, Denmark \\ ${ }^{2}$ Center of Preventive Medicine, Glostrup University Hospital, Copenhagen, Denmark
}

Summary The family of insulin receptor substrates (IRS1-4) is defined by proteins with an overall similar structure. IRS-1 and IRS-2 have been shown to have key roles in cellular transmission of the action of insulin, insulin-like growth factor-1 and various cytokines. We have previously identified amino acid polymorphisms in the human IRS-1 and IRS-2 proteins. Given the documented importance of IRS-1 and -2 in insulin signalling and the implications of distribution of these genes for the pathogenesis of insulin resistance and diabetes, we decided that the most recently identified member of the IRS family, IRS-4, was a relevant candidate to examine for genetic variability which might be associated with subsets of diabetes or insulin resistance. The gene encoding IRS-4 was analysed by the single strand conformation polymorphism technique in 83 Danish Caucasians with Type II (non-insulin-dependent) diabetes mellitus. Five amino acid polymorphisms were identified: Leu34Phe, Arg411Gly, Gly584Cys, His879Asp and Lys883Thr. In an association study of 324 patients with Type II diabetes and 267 control subjects with normal glucose tolerance the polymorphism at codon 34 was found with allelic frequencies of 3.9 and $2.3 \%$, respectively, the variant at codon 411 with allelic frequencies of 3.9 and $5.6 \%$, respectively, and the vari- ant at codon 879 with frequencies of 19.2 and $18.0 \%$, respectively. Each carrier of the codon 34 polymorphism was also a carrier of the codon 411 and codon 879 variants and similarly, carriers of the variant at codon 411 were also carriers of the polymorphism at codon 879 . The variants at codon 584 and 883 were each found in only one Type II diabetic patient. The allelic frequencies of the variants at codon 411 and 879 were also determined in 380 young healthy subjects (4.6 and $18.1 \%$, respectively). The insulin sensitivity index as estimated by Bergman's minimal model of the young healthy subjects carrying either polymorphism was indistinguishable from the carriers of wild-type IRS-4. Moreover, none of the men were heterozygous for the IRS-4 polymorphisms indicating that the gene is located on the X-chromosome. In conclusion, amino acid polymorphisms in human IRS-4 are common in Caucasians but are not associated with Type II diabetes or with insulin resistance in young healthy subjects. [Diabetologia (1998) 41: 969-974]

Keywords Genetics, insulin receptor substrate-4, mutations, non-insulin dependent diabetes mellitus, $\mathrm{X}$ chromosome
Received: 25 February 1998 and in revised form: 7 May 1998

Corresponding author: K. Almind M. Sc., Steno Diabetes Center, Niels Steensensvej 2, DK-2820 Gentofte, Denmark Abbreviations: IRS, insulin receptor substrate; SSCP, single strand conformation polymorphism; $\mathrm{PH}$, pleckstrin homology; $\mathrm{PTB}$, phosphotyrosine binding; PCR, polymerase chain reaction.
Recent studies have identified a family of insulin receptor substrates (IRS1-4) [1,2,3]. The insulin receptor substrates are cytoplasmic docking proteins which undergo tyrosine phosphorylation upon stimulation with insulin, insulin-like growth factor-1 and various cytokines [4]. The overall structure of the insulin receptor substrates is the same, with a N-terminal pleckstrin homology $(\mathrm{PH})$ domain followed by a phosphotyrosine binding (PTB) domain. These do- 
mains have a high degree of homology among the members of the IRS family $[2,3]$. In addition, the IRS proteins have several potential tyrosine phosphorylation sites located in motifs (YXXM) expected to bind specific $\mathrm{SH} 2$ domain containing proteins. Studies of IRS1-4 have shown that, although the signalling properties of the IRSs overlap, they are not functionally interchangeable proteins $[5,6]$. IRS-1 and IRS-2 are the best characterized insulin receptor substrates. They have been shown to play key roles in intracellular insulin signalling. The importance of IRS-1 has been illustrated in IRS- 1 deficient mice which exhibit a 50 to $60 \%$ intrauterine growth retardation and abnormal glucose metabolism due to resistance to the action of insulin and insulin-like growth factor-1, despite the presence of IRS-2 [7]. Similarly, the importance of IRS-2 was described most recently in a study of IRS-2 deficient mice [8]. These mice exhibited insulin resistance in both skeletal muscle and liver and they developed diabetes at an early age as a consequence of an insufficient insulin secretion to compensate for the insulin resistance. Because of the importance of IRS- 1 and IRS- 2 in insulin signalling, we previously scanned the human genes encoding the two proteins to find whether variations of the genes were associated with Type II diabetes or subtypes of the insulin resistance syndrome. In IRS-1 we identified a common glycine to arginine amino acid polymorphism at codon 972 and clinical studies suggest that the heterozygous form of the polymorphism potentiates the obesity associated insulin resistance by about $50 \%[9,10]$. Furthermore, transfection studies of the IRS-1 mutation show that the cells expressing the variant protein have impaired insulin signalling through the phosphatidylinositol 3kinase pathway [11]. In IRS-2 we discovered a frequent glycine to aspartic acid amino acid polymorphism at codon 1057 [12]. This amino acid polymorphism was not associated with random Type II diabetes in Danish Caucasian subjects but it remains to be elucidated whether the polymorphism is associated with insulin resistant subtypes of Type II diabetes, impaired glucose tolerance or impaired insulin secretion.

The gene encoding the human IRS-4 protein was described most recently as a novel member of the IRS family [3]. The protein was identified in human embryonic kidney cells where it undergoes rapid tyrosine phosphorylation in response to insulin stimulation [3]. The tissue distribution and the importance of IRS-4 in insulin signalling remains to be determined. Since the overall structure of IRS-4 is similar to the rest of the IRS proteins, we decided to examine for genetic variability of the human IRS-4 and to ascertain whether any genetic variability was associated with Type II diabetes or insulin resistance.

\section{Subjects and methods}

Study groups. The mutation screening by single strand conformation polymorphism (SSCP) was carried out on 83 Danish Type II diabetic patients of Caucasian origin selected from a group of 324 unrelated Danish Caucasians with Type II diabetes who tested negative for anti GAD antibodies and who were consecutively recruited from the outpatient clinic at Steno Diabetes Center. Association studies were performed on the 324 unrelated Danish Caucasian Type II diabetic patients and 267 unrelated, glucose tolerant Danish Caucasian control subjects who were matched for age, traced in the Danish Central Population Register and who were living in the same area of Copenhagen as the Type II diabetic patients. A 75-g oral glucose tolerance test with measurements in duplicate of plasma glucose, serum insulin and serum C-peptide at 0, 30, 60 and $120 \mathrm{~min}$ had been performed previously on the glucose tolerant control subjects.

The other study group for genotype-phenotype interaction studies comprised 380 Danish Caucasians recruited randomly from young people aged 18-32 years, who in 1979-1980 and again in 1984-1985 as children had participated in blood pressure surveys in a representative and specified part of Copenhagen city [13]. These people had undergone an intravenous glucose tolerance test in combination with intravenous injection of tolbutamide. Insulin sensitivity index was calculated in accordance to Bergman's minimal model [14]. The physiological characteristics of the subjects have been presented previously [13]. Prior to participation in the study, informed consent was obtained from all subjects. The studies were approved by the ethical committee of Copenhagen and were in accordance with the principles of the Declaration of Helsinki.

Glucose in plasma was measured by an automated glucose oxidation method (Granutest; Merck, Darmstadt, Germany). Serum insulin was determined by enzyme linked immuno-adsorbent assay (ELISA) with a narrow specificity - excluding $\operatorname{des}(31,32)$ - and intact proinsulin, using the DAKO insulin kit with overnight incubation (DAKO Diagnostics Ltd, Ely, UK) [15]. The serum concentration of C-peptide was determined by radioimmunoassay (RIA) using the polyclonal antibody M1230.

SSCP-heteroduplex analysis. Genomic DNA was obtained from human leucocyte nuclei isolated from whole blood by digestion with proteinase $\mathrm{K}$ followed by phenol extraction on an Applied Biosystems 341 Nuclei Acid Purification System (Applied Biosystems Inc., Foster City, Calif., USA). PCR amplification was carried out in 96-well microtitre plates on $100 \mathrm{ng}$ of genomic DNA in a total volume of $25 \mu \mathrm{l}$. The assay conditions were: $10 \mathrm{mmol} / \mathrm{l}$ Tris- $\mathrm{HCl}(\mathrm{pH} 9.0), 50 \mathrm{mmol} / \mathrm{l} \mathrm{KCl}$, $1.5 \mathrm{mmol} / 1 \quad \mathrm{MgCl}_{2}, \quad 0.1 \%$ Triton X-100, 0-8\% DMSO, $0.2 \mathrm{mmol} / \mathrm{l} \mathrm{dNTP}$ 's, $0.2 \mu \mathrm{M}$ of each oligonucleotide primer, 0.6 U Taq DNA polymerase (Perkin Elmer, Foster City, Calif., USA) and $0.8 \mu \mathrm{Ci}\left[\alpha^{-}{ }^{32} \mathrm{P}\right] \mathrm{dCTP}$ (Amersham, Buckinghamshire, UK). After an initial denaturation at $95^{\circ} \mathrm{C}$ for 4 min the samples were subjected to 30 cycles of amplification: $94^{\circ} \mathrm{C}$ for $1 \mathrm{~min}, 54-66^{\circ} \mathrm{C}$ for $1 \mathrm{~min}$ and $72^{\circ} \mathrm{C}$ for $1 \mathrm{~min}$ with a final extension at $72^{\circ} \mathrm{C}$ for $5 \mathrm{~min}$. The 19 overlapping primers used to amplify the human IRS-4 gene are given in Table 1 . Electrophoresis was carried out on a $38 \times 31 \times 0.04 \mathrm{~cm}$, non-denaturing $5 \%$ acrylamide gel (49:1, acrylamide:bisacrylamide) in $90 \mathrm{mmol} / 1$ Tris-borate, $2.5 \mathrm{mmol} / \mathrm{l}$ EDTA, with either $1 \%$ glycerol at $4{ }^{\circ} \mathrm{C}$ or $5 \%$ glycerol at $25^{\circ} \mathrm{C}$. Both double stranded DNA, formation of heteroduplexes and single stranded DNA can be observed under these conditions. Detection of the bands were carried out as described previously [9]. The seg- 
Table 1. Nucleotide sequence of oligonucleotide primers used for PCR amplification of the human IRS-4 gene

\begin{tabular}{|c|c|c|c|}
\hline Segment & Forward primer $\left(5^{\prime} \rightarrow 3^{\prime}\right)$ & Reverse primer $\left(5^{\prime} \rightarrow 3^{\prime}\right)$ & Size (bp) \\
\hline 1 & СТТААААССАТССТССАТСАС & GCGTTTGCAGAGACTTCCTCCCC & 270 \\
\hline 2 & CACTCATTGGGACCGGGTCG & CGGCCGCCGCTGCTGCAGCC & 273 \\
\hline 3 & GAATACTACGAAAATGCCAG & GGATGAGGCGGCTGAGCAGC & 270 \\
\hline 4 & CGCGATGGTGGCCGAGAACG & TCACAAACACGACCTCCTCG & 269 \\
\hline 5 & GGCACAGAAAAGAGCTGAGC & TATTCGTCTGCACACAAGGC & 274 \\
\hline 6 & TGTGGTTGCCCAAAACATGC & CTCGCTGGGTGTTACGAAGG & 271 \\
\hline 7 & ACCTCAGGGCCATCGGCGACG & TGGGGATTGCCTТССТСССС & 280 \\
\hline 8 & GAAGCCCCGAACAATGGAGC & TGGCCATTTGAGCCCTGACC & 272 \\
\hline 9 & GGAGGAAACCAGTGTTCAGG & GAGTTAATTTGCCAAAATAGG & 310 \\
\hline 10 & GAAAGGATCCGATGGTGATGG & TGGGGACCTCGAGCTGCACC & 270 \\
\hline 11 & CGAAAGAATGCAAAGAAGCC & GGTGGTGGGCTCACTCTGGG & 272 \\
\hline 12 & AAGCGCCACTCTCGATCCCC & AAGGTGAGCTCCGAAAAGGG & 272 \\
\hline 13 & СТCAGGGTGGCTCTTССТCC & TGGGGGCTCATGATCTGAAGG & 260 \\
\hline 14 & TGAGGGATCATTCTCAAAGC & ATTATGCCCCACGAATCTGG & 264 \\
\hline 15 & GACTTCACTAAAAGAGAGAGC & СТСТТССТСААТАGСАТTGC & 268 \\
\hline 16 & AGTGCTAGGTGGCCACTTCC & ТTCTCTCCTGCTCTTCTTCCTGC & 274 \\
\hline 17 & АТTТСТСТСТСССССАGCCG & TGCTGCGCCGATGCCCGGGGG & 276 \\
\hline 18 & GCCGACTTTAGCCCTCAGCC & CGGCAGCTGCAGCGGCAGCC & 263 \\
\hline 19 & CCACAACCCATCTGCAAACC & GAAATATACCCTAACACTGTAG & 290 \\
\hline
\end{tabular}

ments which showed aberrant mobility were sequenced and analysed on an ABI 377 automated sequencer (Applied Biosystems Inc).

Detection of amino acid polymorphisms in human IRS-4. The amino acid substitution Leu34Phe caused by a CTT $\rightarrow$ TTT substitution was detected by making a 190-bp radioactive polymerase chain reaction (PCR) amplified segment using the reverse primer 1 (Table 1 ) and a long forward primer with a non-annealing tail to avoid any additional enzyme restriction sites for the enzyme AciI (New England BioLabs Inc., Beverly, Mass., USA). After digestion with AciI the wild-type allele showed three bands of 100, 65 and $25 \mathrm{bp}$, respectively and the homozygous allele showed two bands of 100 and $90 \mathrm{bp}$. The fragments were separated on a $6 \%$ denaturing sequencing gel (Life Technologies, Gibco BRL, Paisley, UK). The Arg411His caused by a double nucleotide substitution (CGA $\rightarrow$ CAT) was detected by PCR amplifying a segment of 691 bp (segment 5-7 in Table 1) followed by restriction enzyme digestion with Nla III. DNA fragments were separated by electrophoresis on a $3 \%$ high resolution agarose gel containing ethidium bromide to make them visible. The wild-type allele shows two bands of approximately 238 and $458 \mathrm{bp}$, whereas the mutant allele shows three bands of 188, 238 and 270 bp, respectively. Detection of amino acid variant Gly584Cys (GGT $\rightarrow$ TGT) was performed by PCR amplifying a segment of 520 bp (segment $8-9$, Table 1) and digestion with $X \mathrm{cmI}$. Restriction enzyme digestion of the wild-type allele results in three bands of 117, 178 and $225 \mathrm{bp}$, respectively and digestion of the mutant allele results in two bands of 178 and $342 \mathrm{bp}$. The amino acid substitution His879Asp (CAT $\rightarrow$ GAT) was detected by amplifying a 265-bp segment (segment 14 in Table 1) followed by digestion with DpnII resulting in three bands from the wild-type allele of 20,27, $212 \mathrm{bp}$, respectively and two bands from the mutant allele of 27 and $232 \mathrm{bp}$. The nucleotide substitution (AAG $\rightarrow$ ACG) creating the polymorphism Lys883Thr did not create or disrupt a recognition site for a restriction enzyme. A restriction site for the restriction enzyme MboII was created by using a long oligonucleotide primer containing a nucleotide mismatch. The PCR amplified product of $436 \mathrm{bp}$ was digested with $\mathrm{MboII}$ and the wild-type allele gave rise to two bands of 57 and $379 \mathrm{bp}$, respectively and the mutant allele to one band of $436 \mathrm{bp}$.
Statistics. A Mann-Whitney test was used for comparison between groups. Statistical Package of Social Science (SPSS) for Windows, version 6.01, was used for statistical analysis. A $p$ value less than 0.05 (two-tailed) was considered significant.

\section{Results}

SSCP scanning and nucleotide sequencing of the human IRS-4 gene. The SSCP scanning of IRS-4 was carried out in 19 overlapping segments on 83 Danish Caucasian Type II diabetic patients. The scanning showed seven different aberrant migrating profiles. Subsequent nucleotide sequencing revealed two frequent and coupled silent polymorphisms, GCG $\rightarrow$ GCA at codon 20 (alanine) and likewise, GCG $\rightarrow$ GCA at codon 21 (alanine) with an allelic frequency of approximately $23 \%$. Another silent polymorphism (GGC $\rightarrow$ GGT) was detected at codon 504 (glycine) with allelic frequency of approximately $17 \%$. At codon 34 , the sequencing showed a nucleotide change $(\mathrm{CTT} \rightarrow$ TTT) resulting in a leucine to a phenylalanine substitution (Fig.1) and at codon 411, the sequencing showed a double nucleotide substitution (CGA $\rightarrow$ CAT) causing a change of an arginine to a histidine. These amino acid polymorphisms were primarily found in 9 of the 83 Type II diabetic patients in either the heterozygous or the homozygous form. Two rare nucleotide substitutions (GGT $\rightarrow$ TGT at codon 584 and AAG $\rightarrow$ ACG at codon 883 ) were each discovered in only one Type II diabetic patient. The nucleotide substitution at codon 584 caused a change of a glycine to a cysteine and the nucleotide substitution at codon 883 resulted in a change of a lysine to a threonine. Sequencing of the last aberrant migrating SSCP segment showed a heterozygous or homozygous CAT $\rightarrow$ GAT substitution 


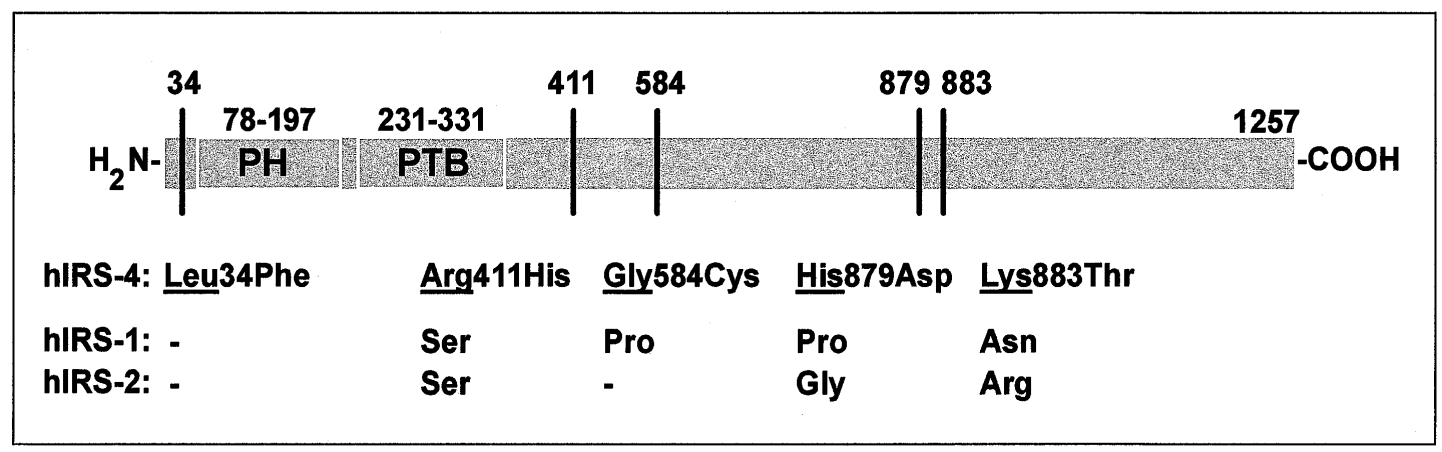

Fig. 1. Location of amino acid variants identified in human IRS-4. Position of the 5 amino acid variants in IRS- 4 and the PH (pleckstrin homology) and PTB (phosphotyrosine binding) domains are shown. Amino acids at codon 34, 411, 584, 879 and 883 in hlRS-4 are underlined and the amino acids at similar positions in hlRS-1 and -2 are indicated below

in 23 of the 83 Type II diabetic patients which resulted in a histidine to an aspartic acid replacement at codon 879 .

Association studies of amino acid polymorphisms in IRS-4. The allelic frequency of the five amino acid polymorphisms discovered in IRS-4 was determined in 324 Type II diabetic patients and in 267 control subjects. The amino acid variants at codon 584 and 883 were rare and each of them was found in the heterozygous form in only one Type II diabetic patient. The amino acid polymorphisms at codon 34 and 411 were more common and the variant at codon 34 was found with allelic frequencies of $3.9 \%$ (95\% confidence interval: $2.1-5.7$ ) in Type II diabetes and $2.3 \%$ (0.7-3.9) in normal glucose tolerant subjects $(p=0.23)$ whereas the variant at codon 411 was found with an allelic frequency of $3.9 \%(1.8-6.0)$ in Type II diabetes and $5.6 \%(2.8-8.4)$ in normal glucose tolerant subjects $(p=0.22)$. The most prevalent variant of IRS-4 was the polymorphism at codon 879 with allelic frequencies of $19.2 \%$ (14.9-23.5) compared with $18.0 \%(13.4-22.6)$ in Type II diabetic patients and control subjects, respectively $(p=0.70)$. Furthermore, carriers of the amino acid substitution at codon 34 were carriers of the amino acid substitution at codon 411 and 879 as well and the polymorphism at 411 and 879 were also coupled. Interestingly, among men there were only homozygous carriers and no heterozygous carriers of either of the IRS- 4 polymorphisms. This indicates that the gene encoding IRS-4 is located on the X-chromosome. The genotype frequencies were in Hardy-Weinberg equilibrium when estimated for women and men, separately.

Additionally, the frequencies of the most common amino acid variants in IRS-4 were determined in a previously characterized group [13] of 380 young healthy Danish Caucasians in order to make an extended study of the clinical characteristics of the
IRS-4 polymorphism carriers. In this cohort the allelic frequency of the variant at codon 411 was $4.6 \%$ (2.5-6.7) and the frequency of the variant at codon 879 was $18.1 \%(14.2-22.0)$.

Clinical characteristics of middle-aged glucose tolerant subjects and young healthy subjects carrying IRS4 polymorphisms. Comparative studies of phenotype and genotype in 229 subjects from the cohort of 267 middle-aged control subjects and in 367 subjects from the cohort of 380 young healthy subjects showed that the clinical and biochemical characteristics of heterozygous or homozygous subjects carrying the arginine to histidine amino acid polymorphism at codon 411 were identical to wild-type carriers (data not shown). Similarly, the characteristics of the carriers of the heterozygous or homozygous histidine to aspartic acid substitution at codon 879 were indistinguishable from the wild-type carriers (results not shown). Since IRS-4 seems to be located on the Xchromosome women and men were analysed separately to determine if the frequent amino acid polymorphism at codon 879 had a more pronounced impact on glucose homeostasis and insulin sensitivity in one of the groups (Table 2 and 3 ). There was no difference between the group of wild-type carriers or polymorphism carriers of the variant at codon 879 in either the group of middle-aged glucose tolerant subjects or the young healthy subjects. The subjects carrying the polymorphism at codon 411 were also carriers of the amino acid change at codon 879 . Therefore, the group carrying the polymorphism at codon 879 exclusively was in addition analysed separately but the subject did not show any phenotypic difference from the rest of the group (results not shown).

\section{Discussion}

Several nucleotide substitutions were discovered in IRS-4 of which five predicted amino acid changes. The substitutions at codon 34, 584 and 883 are rare and their potential impact on the risk of diabetes or insulin resistance cannot be evaluated from the present study material. The arginine to histidine variant at codon 411 was similar in diabetic and control sub- 
Table 2. Clinical and biochemical characteristics of middle-aged women $(n=115)$ and men $(n=114)$ with normal glucose tolerance carrying wild-type IRS-4 or the heterozygous (women only) or homozygous His879Asp polymorphism in IRS-4

\begin{tabular}{lllll}
\hline & $\begin{array}{l}\text { Wild-type } \\
\text { codon } 879\end{array}$ & $\begin{array}{l}\text { Heterozygous } \\
\text { codon } 879\end{array}$ & $\begin{array}{l}\text { Homozygous } \\
\text { codon } 879\end{array}$ & $p$ \\
\hline Number (women/men) & $77 / 96$ & $32 / 0$ & $6 / 18$ & \\
Age (years) & $49(13) / 56(14)$ & $47(12)$ & $50(11) / 57(15)$ & $23(2) / 26(4)$ \\
BMI (kg/m $\left.{ }^{2}\right)$ & $25(5) / 26(3)$ & $25(4)$ & $0.78(0.03) / 0.94(0.09)$ & $0.71 / 0.71$ \\
Waist-hip ratio & $0.83(0.14) / 0.93(0.07)$ & $0.81(0.15)$ & $5.3(0.5) / 5.0(0.4)$ & $0.64 / 0.77$ \\
F-p-glucose (mmol/l) & $5.0(0.5) / 5.3(0.5)$ & $5.0(0.5)$ & $48(21) / 41(18)$ \\
F-s-insulin $(\mathrm{pmol} / \mathrm{l})$ & $41(21) / 44(24)$ & $36(18)$ & $596(171) / 582(197)$ & $0.30 / 0.08$ \\
F-s-C-peptide $(\mathrm{pmol} / \mathrm{l})$ & $534(149) / 580(164)$ & $519(141)$ & $40(19) / 40(18)$ & $0.34 / 0.74$ \\
AUC glucose $(\mathrm{pmol} / \mathrm{l})$ & $37(17) / 43(19)$ & $36(18)$ & $5658(1607) / 7440(3857)$ \\
AUC insulin $(\mathrm{pmol} / \mathrm{l})$ & $6212(4113) / 6983(4326)$ & $6474(2796)$ & $32238(4758) / 32144(12186)$ & $0.94 / 0.50$ \\
AUC C-peptide $(\mathrm{pmol} / \mathrm{l})$ & $31951(13284) / 33732(14070)$ & $33448(9606)$ & $0.47 / 0.86$ \\
\hline
\end{tabular}

Data represent mean (SD)

AUC (area under the curve) refers to plasma glucose, serum insulin and serum C-peptide responses for 0-30 min after an oral glucose tolerance test. The responses were calculated by means of the trapezoidal rule as the incremental values, i.e. area under the curves when expressed above basal values. $\mathrm{F}$ denotes fasting, $\mathrm{s}$ denotes serum and $\mathrm{p}$ denotes plasma. $P$-values compare for each gender subjects homozygous for the codon 879 variant to wild-type carriers.

Table 3. Clinical and biochemical characteristics of young healthy women $(n=188)$ and men $(n=179)$ with normal glucose tolerance carrying wildtype IRS-4 or the heterozygous (women only) or homozygous His879Asp polymorphism in IRS-4

\begin{tabular}{|c|c|c|c|c|}
\hline & $\begin{array}{l}\text { Wild-type } \\
\text { codon } 879\end{array}$ & $\begin{array}{l}\text { Heterozygous } \\
\text { codon } 879\end{array}$ & $\begin{array}{l}\text { Homozygous } \\
\text { codon } 879\end{array}$ & $p$ \\
\hline men/women & $125 / 150$ & $55 / 0$ & $8 / 29$ & \\
\hline Age (years) & $25(4) / 26(4)$ & $26(3)$ & $25(7) / 26(3)$ & $0.85 / 0.69$ \\
\hline $\mathrm{BMI}\left(\mathrm{kg} / \mathrm{m}^{2}\right)$ & $23(4) / 24(3)$ & $23(4)$ & $25(7) / 24(4)$ & $0.28 / 0.74$ \\
\hline Waist-hip ratio & $0.77(0.05) / 0.86(0.05)$ & $0.78(0.08)$ & $0.78(0.04) / 0.86(0.05)$ & $0.49 / 0.88$ \\
\hline F-p-glucose (mmol/l) & $4.8(0.4) / 5.2(0.5)$ & $4.9(0.3)$ & $5.0(0.5) / 5.1(0.4)$ & $0.34 / 0.75$ \\
\hline F-s-insulin (pmol/l) & $37(21) / 36(21)$ & $44(25)$ & $45(25) / 32(16)$ & $0.42 / 0.53$ \\
\hline F-s-C-peptide (pmol/l) & $485(146) / 459(162)$ & $499(183)$ & $586(223) / 439(137)$ & $0.26 / 0.57$ \\
\hline Acute s-insulin response $\mathrm{a}^{\mathrm{a}}$ & $42(27) / 35(20)$ & $43(29)$ & $49(27) / 33 \pm 23$ & $0.31 / 0.41$ \\
\hline Acute s-C-peptide response $\mathrm{a}^{\mathrm{a}}$ & $130(56) / 116(48)$ & $124(52)$ & $134(67) / 118(52)$ & $0.99 / 0.99$ \\
\hline Insulin sensitivity ${ }^{\mathrm{b}}$ & $15.5(9.1) / 15.0(8.2)$ & $14.7(11.0)$ & $14.0(12.3) / 17.0(11.9)$ & $0.35 / 0.79$ \\
\hline
\end{tabular}

Data represent mean (SD). F denotes fasting, s denotes serum and $\mathrm{p}$ denotes plasma.

${ }^{a}$ Acute insulin and C-peptide responses during 0-8 min after intravenous injection of $0.3 \mathrm{~g} / \mathrm{kg}$ body weight of $50 \%$ glucose were calculated by means of the trapezoidal rule as the incre-

jects and, furthermore, carriers of the polymorphism were compound carriers of this variant and the histidine to aspartic acid substitution at codon 879 . The group of normal glucose tolerant middle-aged subjects carrying the compound mutations showed no differences in clinical or biochemical characteristics when compared with the group without the compound polymorphisms. Likewise, when a group of young healthy subjects was analysed for the compound IRS-4 polymorphisms; there was no difference during the intravenous glucose tolerance test between subjects with or without the amino acid changes. The polymorphism at codon 879 was the most frequent variant identified in IRS-4 but the allelic frequencies determined in Type II diabetic patients and control subjects showed a lack of association to Type II diabetes. The biochemical and clinical data of normal glucose tolerant middle-aged subjects with the codon 879 polymorphism were identical to wild-type mental values (area under the curve when expressed above basal values).

b Insulin sensitivity index estimated by Bergman's minimal model $\left(\times 10^{-5} 1 \cdot \mathrm{min}^{-1} \cdot \mathrm{pmol}^{-1}\right)$.

$P$-values compare for each gender subjects homozygous for the codon 879 variant to wild-type carriers.

carriers and there also appeared to be no differences among young healthy subjects either carrying the polymorphism or carrying two wild-type alleles.

Since no heterozygous men were found, indicating a localization of IRS-4 to the X-chromosome, it was relevant to make analyses of the women and men carriers as two separate groups. A minor impact on insulin sensitivity or glucose homeostasis, especially of the frequent polymorphism at codon 879 , might be easier to detect, especially in men carrying only the variant IRS-4 proteins. The phenotype of male polymorphism carriers was not different, however, from the phenotype of men having the normal IRS-4 protein. The subjects who are compound polymorphism carriers (at codon 411 and 879) lose a histidine residue at codon 879 but regain a histidine residue due to the amino acid change at codon 411 . Thus, we looked at carriers of the codon 879 variant who did not have the amino acid substitution at codon 411 to 
determine if this histidine disruption or displacement had any measurable impact on glucose homeostasis, insulin secretion or insulin sensitivity. Nevertheless, the phenotype of subjects who only carried the histidine to aspartic acid substitution at codon 879 did not differ from the phenotype of other subjects.

Our results showing no obvious alterations in phenotype characteristics in carriers of IRS-4 polymorphisms can putatively be explained by none of the amino acid changes in IRS-4 being conserved in human IRS-1 or IRS-2 (Fig. 1) [12] or being located at or near to any of the 12 potential IRS- 4 tyrosine phosphorylation sites described by Lavan et al. [3]. Only 7 of the 12 tyrosine phosphorylation sites (Tyr-487, $-700,-717,-743,-779,-828$, and -921$)$ are placed in YXXM motifs which are known to bind to $\mathrm{SH} 2$ domains of PI 3-kinase. Moreover, the tyrosine residue at codon 921 is placed in a motif which could be a binding site for Grb-2 and another tyrosine residue at codon 1015 is a possible binding site for SHP-2 or phospholipase $C \gamma$ [3]. It remains to be shown which of the IRS-4 tyrosine residues are actual binding sites for downstream signalling molecules. The five identified amino acid changes of IRS-4 are furthermore located at some distance from the pleckstrin homology (PH) domain and the phosphotyrosin binding (PTB) domain which are known to be important for the interaction of both IRS-1 and IRS-2 with the insulin receptor and other signalling proteins [1]. In addition to the PTB domain there are other domains of IRS-1 and IRS-2 which are important for the interaction with the insulin receptor [1].The identity and importance of similar domains in IRS-4 remain to be determined. A more thorough investigation of the relative importance of IRS-4 for specific actions of insulin in a given tissue is still needed. IRS-4 could have only a minor role in insulin action in classical target tissues but it may have a major role in other tyrosine phosphorylation mediated events for which the physiological endpoints have not yet been identified.

Acknowledgements. This study was supported by grants from the University of Copenhagen, the Danish Medical Research Council, the Danish Diabetes Association, the Velux Foundation and EEC (BMH4-CT-950 662). The authors wish to thank Annemette Forman, Bente Mottlau, Lene Aabo, Sandra Urioste, Lisbeth Drastrup, Susanne Kjellberg and Jane Broennum for technical assistance and Grete Lademann for secretarial assistance.

\section{References}

1. Yenush L, White MF (1997) The IRS-signalling system during insulin and cytokine action. Bioessays 19: 491-500

2. Lavan BE, Lane WS, Lienhard GE(1997) The 60-kda phosphotyrosine protein in insulin-treated adipocytes is a new member of the insulin-receptor substrate family. J Biol Chem 272: 11439-11443

3. Lavan BE, Fantin VR, Chang ET, Lane WS, Keller SR, Lienhard GE (1997) A novel 160-kda phosphotyrosine protein in insulin-treated embryonic kidney-cells is a new member of the insulin-receptor substrate family. J Biol Chem 272: 21403-21407

4. White MF (1996) The IRS-signalling system in insulin and cytokine action. Philosophical Transactions of the Royal Society of London Series B- biological Sciences 351: 181-189

5. Bruning JC, Winnay J, Cheatham B, Kahn CR (1997) Differential signalling by insulin-receptor substrate-1 (IRS-1) and IRS-2 in IRS-1-deficient cells. Mol Cell Biol 17: 1513-1521

6. Fantin VR, Sparling JD, Slot JW, Keller SR, Lienhard GE, Lavan BE (1998) Characterization of insulin receptor substrate 4 in human embryonic kidney 293 cells. J Biol Chem 273: 10726-10732

7. Araki E, Lipes MA, Patti ME et al. (1994) Alternative pathway of insulin signalling in mice with targeted disruption of the IRS-1 gene. Nature 372: 186-190

8. Withers DJ, Gutierrez JS, Towery H et al. (1998) Disruption of IRS-2 causes Type II diabetes in mice. Nature 391: 900-904

9. Almind K, Bjorbaek C, Vestergaard H, Hansen T, Echwald S, Pedersen O (1993) Amino-acid polymorphisms of insulin-receptor substrate-1 in non-insulin- dependent diabetes-mellitus. Lancet 342: 828-832

10. Clausen JO, Hansen T, Bjorbaek C et al. (1995) Insulin-resistance - interactions between obesity and a common variant of insulin-receptor substrate-1. Lancet 346: 397-402

11. Almind K, Inoue G, Pedersen O, Kahn CR (1996) A common amino acid polymorphism in insulin-receptor substrate-1 causes impaired insulin signalling - evidence from transfection studies. J Clin Invest 97: 2569-2575

12. Bernal D, Almind K, Yenush L et al. (1998) IRS-2 amino acid polymorphisms are not associated with random type 2 diabetes among Caucasians. Diabetes 41: 976-979

13. Clausen JO, Borch-Johnsen K, Ibsen H et al. (1996) Insulin sensitivity index, acute insulin-response, and glucose effectiveness in a population-based sample of 380 young healthy Caucasians - analysis of the impact of gender, body fat, physical-fitness, and life-style factors. J Clin Invest 98: 1195-1209

14. Steil GM, Volund A, Kahn SE, Bergman RN (1993) Reduced sample number for calculation of insulin sensitivity and glucose effectiveness from the minimal model - suitability for use in population studies. Diabetes 42: 250-256

15. Andersen L, Dinesen B, Jorgensen PN, Poulsen F, Roder ME (1993) Enzyme-immunoassay for intact human insulin in serum or plasma. Clin Chem 39: 578-582 